\title{
Nitric oxide is a positive regulator of the Warburg effect in ovarian cancer cells
}

\author{
CA Caneba ${ }^{1,2,6}$, L Yang ${ }^{1,3,6}$, J Baddour ${ }^{1,3}$, R Curtis $^{1,3}, \mathrm{~J} \mathrm{Win}^{1,3}$, S Hartig ${ }^{4}$, J Marini ${ }^{*, 4,5}$ and D Nagrath ${ }^{*, 1,2,3}$
}

Ovarian cancer (OVCA) is among the most lethal gynecological cancers leading to high mortality rates among women. Increasing evidence indicate that cancer cells undergo metabolic transformation during tumorigenesis and growth through nutrients and growth factors available in tumor microenvironment. This altered metabolic rewiring further enhances tumor progression. Recent studies have begun to unravel the role of amino acids in the tumor microenvironment on the proliferation of cancer cells. One critically important, yet often overlooked, component to tumor growth is the metabolic reprogramming of nitric oxide (NO) pathways in cancer cells. Multiple lines of evidence support the link between NO and tumor growth in some cancers, including pancreas, breast and ovarian. However, the multifaceted role of NO in the metabolism of OVCA is unclear and direct demonstration of NO's role in modulating OVCA cells' metabolism is lacking. This study aims at indentifying the mechanistic links between NO and OVCA metabolism. We uncover a role of NO in modulating OVCA metabolism: NO positively regulates the Warburg effect, which postulates increased glycolysis along with reduced mitochondrial activity under aerobic conditions in cancer cells. Through both NO synthesis inhibition (using L-arginine deprivation, arginine is a substrate for NO synthase (NOS), which catalyzes NO synthesis; using L-Name, a NOS inhibitor) and NO donor (using DETA-NONOate) analysis, we show that NO not only positively regulates tumor growth but also inhibits mitochondrial respiration in OVCA cells, shifting these cells towards glycolysis to maintain their ATP production. Additionally, NO led to an increase in TCA cycle flux and glutaminolysis, suggesting that NO decreases ROS levels by increasing NADPH and glutathione levels. Our results place NO as a central player in the metabolism of OVCA cells. Understanding the effects of NO on cancer cell metabolism can lead to the development of NO targeting drugs for OVCAs.

Cell Death and Disease (2014) 5, e1302; doi:10.1038/cddis.2014.264; published online 26 June 2014

Despite recent medical and pharmaceutical advances in cancer research, ovarian cancer (OVCA) remains one of the most deadly gynecological malignancies, with most of the cancer first detected in late stages when metastasis has already occurred. ${ }^{1}$ Only $20 \%$ of OVCA patients are diagnosed when cancer has not spread past the ovaries; in the other $80 \%$ of cases, the cancer has metastasized, most frequently to the peritoneum. ${ }^{2}$ Platinum-based preoperative chemotherapy is the standard of care of early stage disease, and surgical resection along with platinum-based postoperative chemotherapy is the standard of care for late stage disease. ${ }^{1}$ However, many platinum-based chemotherapy drugs come with unwanted side effects. Therefore, an alternative therapy for OVCA is needed.

Nitric oxide (NO) shows promise either as a cancer therapeutic agent by itself or as a target of cancer therapies. ${ }^{3}$ This may be because NO can act as a signaling molecule or as a source of oxidative and nitrosative stress. ${ }^{4} \mathrm{NO}$ can stimulate mitochondrial biogenesis through PGC-1-related coactivator $^{5}$ and increase mitochondrial function. ${ }^{6,7}$ In follicular thyroid carcinoma cells, S-nitroso- $N$-acetyl-D, L-penicillamine (SNAP), a NO donor, was shown to increase the expression of genes involved in mitochondrial biogenesis. ${ }^{8,9}$ A 14-day treatment of lung carcinoma cells with dipropylenetriamine NONOate (DETA-NONOate), another NO donor, increased cell migration compared with the absence of treatment. ${ }^{10}$ In breast cancer cells, exogenous NO increased cell proliferation, as well as cyclin-D1 and ornithine decarboxylase expression. ${ }^{11}$ In prostate cancer cells, NO was shown to inhibit androgen receptor-dependent promoter activity and proliferation of androgen-dependent cells, indicating that NO would select for the development of prostate cancer cells that are androgen-independent. ${ }^{12}$ NO has even been shown to inhibit mitochondrial ATP production, and therefore inhibit apoptosis, as ATP is necessary for the apoptotic process. ${ }^{13}$ Moreover, inducible nitric oxide synthase (iNOS) knockout mice had less tumor formation than wildtype mice, indicating that NO promotes lung tumorigenesis. ${ }^{14}$

\footnotetext{
${ }^{1}$ Laboratory for Systems Biology of Human Diseases, Rice University, Houston, TX, USA; ${ }^{2}$ Department of Bioengineering, Rice University, Houston, TX, USA; ${ }^{3}$ Department of Chemical and Biomolecular Engineering, Rice University, Houston, TX, USA; ${ }^{4}$ Department of Pediatrics, Baylor College of Medicine, Houston, TX, USA and ${ }^{5}$ Pediatric Critical Care Medicine and USDA/ARS Children's Nutrition Research Center, Baylor College of Medicine, Houston, TX, USA

${ }^{*}$ Corresponding authors: J Marini, Department of Pediatrics, Baylor College of Medicine, Houston, TX 77030-2600, USA. Tel: +1 713 798 0343; Fax: +1 713 798 7101; E-mail: marini@bcm.edu

or D Nagrath, Department of Chemical and Biomolecular Engineering, Rice University, MS-362 Abercrombie Building, 6100 Main Street, Houston, TX 77251-1892, USA. Tel: +1 713348 6408; Fax: +1 713348 5478; E-mail: deepak.nagrath @ rice.edu

${ }^{6}$ These authors contributed equally to this work.

Abbreviations: OVCA, ovarian cancer; NO, nitric oxide; NOS, nitric oxide synthase; iNOS, inducible nitric oxide synthase; eNOS, endothelial nitric oxide synthase; SNAP, S-nitroso-N-acetyl-D,L-penicillamine; DETA-NONOate, dipropylenetriamine NONOate; ASS, argininosuccinate synthase; COX, cytochrome $c$ oxidase; CYTB, cytochrome $b$; ADI PEG-20, pegylated ADI; CCLE, cancer cell line encyclopedia

Received 28.2.14; revised 14.5.14; accepted 16.5.14; Edited by A Finazzi-Agrò
} 
On the other hand, NO production, as induced by proinflammatory cytokines, induced apoptosis in OVCA cells. ${ }^{3}$ NOS overexpression by transfection of a plasmid containing NOS-3 DNA resulted in increased cell death in HepG2 cells. ${ }^{15}$ In another study, NO was implicated in $\mathrm{N}$-(4-hydroxyphenyl) retinamidemediated apoptosis. ${ }^{16}$ Finally, iNOS expression in p53-depleted mice increased apoptosis of lymphoma cells compared with p53-deficient mice without iNOS expression. ${ }^{17}$ Therefore, NO has been seen to have both an anti-tumorigenic as well as a pro-tumorigenic effect.

Arginine, a conditionally essential amino acid used to produce $\mathrm{NO}$, is also a potential target for cancer therapy. L-arginine is normally produced by the body; however, in some diseased states, more arginine than what the body normally produces is required. ${ }^{18}$ Arginine sources include protein breakdown or directly from the diet, in addition to de novo synthesis. ${ }^{19}$ In the de novo production of L-arginine, citrulline and aspartate are first converted to argininosuccinate by arginase, which is then split into arginine and fumarate by argininosuccinate lyase. ${ }^{20} \mathrm{~L}$-arginine can also be converted to citrulline and NO through NO synthase (NOS). ${ }^{19}$ Some cancer cells, including melanoma and hepatocellular carcinoma, do not express argininosuccinate synthase (ASS), an enzyme involved in arginine production and thus rely on exogenous arginine. ${ }^{19}$ For these cancers, arginine-deprivation therapy is being heavily explored as a treatment. ${ }^{21,22}$ OVCA cells have been shown to express ASS. $^{23}$ In fact, OVCA cells were shown to have increased expression of ASS compared with normal ovarian surface epithelium. ${ }^{24}$ As OVCA can synthesize arginine de novo, strategies which target arginine's conversion into citrulline are needed for regulating OVCA tumor growth.

Recent studies suggest that cancer cells undergo metabolic reprogramming, which drives cancer cells' growth and progression. ${ }^{25-33}$ One critically important, yet often overlooked, component to tumor growth is the metabolic rewiring of NO pathways in OVCA cells. Despite considerable investigation on NO's regulation of cancer cell proliferation and growth, mechanistic details regarding the effect of $\mathrm{NO}$ on cancer cell metabolism is still lacking: specifically, how NO affects glycolysis, TCA cycle flux, and ROS production. Studies on the effects of $\mathrm{NO}$ on cancer cell metabolism have mainly focused on the effect of NO on mitochondrial respiration. ${ }^{34-37}$ NO has been shown to inhibit cytochrome $c$ oxidase (COX) in the mitochondria of breast cancer cells, as well as decrease oxygen consumption rate. ${ }^{37-39}$ Moncada and colleagues studied the effect of $\mathrm{NO}$ on the metabolism of rat cortical astrocytes and neurons, two cells with different glycolytic capacities. They showed that NO decreased ATP concentration, which led to an increase in glycolysis in astrocytes, but not in neurons, indicating that glycolytic capacity affects the metabolic response of these cells to NO. ${ }^{40} \mathrm{NO}$ was shown to reduce ATP production via OXPHOS in rat reticulocytes, cells that produce $90 \%$ of their ATP from OXPHOS. ${ }^{41}$ Endothelial NOS (eNOS) was shown to have a role in the upregulation of GLUT4 transporters by AMPK and AICAR in the heart muscle. ${ }^{42}$ Additionally, NO can serve to stabilize HIF-1 $\alpha$ in hypoxic conditions through S-nitrosylation of PHD2, ${ }^{4}$ and as HIF- $1 \alpha$ upregulates GLUT transporters and glycolysis, ${ }^{43} \mathrm{NO}$ may affect the metabolism of cancer cells.
Although NO is found to affect glycolysis of normal cells, how NO modulates glycolysis of OVCA cells is less understood. The multifaceted role of NO in the metabolism of OVCA is unclear, and direct demonstration of NO's role in modulating the metabolism of OVCA cells is lacking. This study aims at understanding the mechanistic links between $\mathrm{NO}$ and the overall cancer metabolism - specifically, its effects on glycolysis, TCA cycle, OXPHOS, and ROS production - of OVCA cells. Our results show that NO decreases mitochondrial respiration, forcing OVCA cells to undergo higher glycolytic rates to maintain ATP production levels. Our work is the first to illustrate the central role of NO on OVCA metabolism - specifically, showing how NO (i) positively regulates the Warburg effect in OVCA cell, (ii) maintains low ROS levels by upregulating NADPH generation, and (ii) negatively alters mitochondrial respiration, thus promoting cancer growth and proliferation. Our work is also unique in that it is the first to explore the effects of NO on TCA cycle flux and glutaminolysis, potentially also affecting ROS levels by affecting antioxidant levels. In conclusion, by elucidating the effects of $\mathrm{NO}$ on cancer metabolism and ROS levels, we have a better understanding of the different mechanisms by which NO affects cancer cell growth. This understanding may lead to potentially useful therapies to halt cancer progression.

\section{Results}

Conversion of arginine to citrulline occurs in OVCA cells. Previously, we observed using ultra-high performance liquid chromatography that OVCA cells produced citrulline in detached conditions. ${ }^{44}$ As arginine can be converted to citrulline through NOS, we hypothesized that arginine is being converted to citrulline in our OVCA cells, even in attached conditions as depicted in Figure 1a. In order to test this hypothesis, we cultured OVCA cells in attached conditions for 24 and $48 \mathrm{~h}$ in media containing guanido- ${ }^{15} \mathrm{~N}_{2}$ arginine, collected media, and analyzed the media using liquid chromatography-mass spectroscopy (LC-MS) for ${ }^{15} \mathrm{~N}$ citrulline, generated through NOS pathway. Results showed that ${ }^{15} \mathrm{~N}$ citrulline was present in the spent media (Figure $1 \mathrm{~b}$ ), confirming that the arginine to citrulline pathway was active in OVCA cells (Figure 1a). Next, we measured the levels of intracellular NO production using Griess assay (Promega, Madison, WI, USA) (measured nitrite levels were indicator of NO) in OVCA cells. OVCA cells generated nanomole range of NO per milligram proteins (Figure 1c). Similar concentrations of NO have been shown to positively regulate cell proliferation. We further investigated the NOS gene expression levels in OVCA cell lines using the cancer cell line encyclopedia (CCLE) database (Figure 1d) and OVCA tumors using Oncomine on 'Bonome Ovarain Data set' (Figure 1e). Interestingly, both aggressive (SKOV3) and less aggressive (OVCAR3) OVCA cell lines used in our study, ${ }^{45}$ had similar levels of gene expression of NOS1, NOS2, and NOS3 (Figure 1d). However, ovarian tumors had higher expression levels of NOS2 (iNOS) and NOS3 (eNOS) compared with ovarian surface epithelial cells from healthy subjects (Figure1e). The above results show that NOS expression levels correlate with increased OVCA pathogenicity. 
a

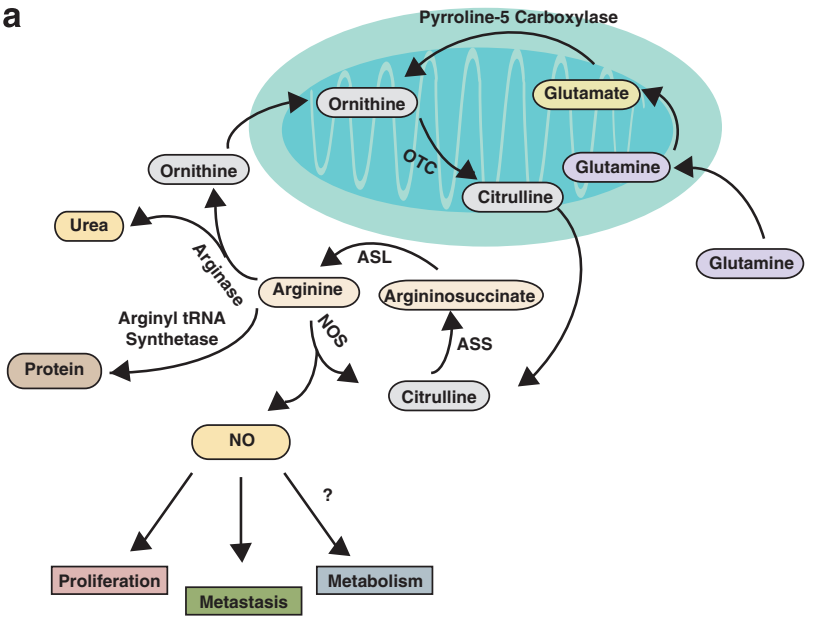

b

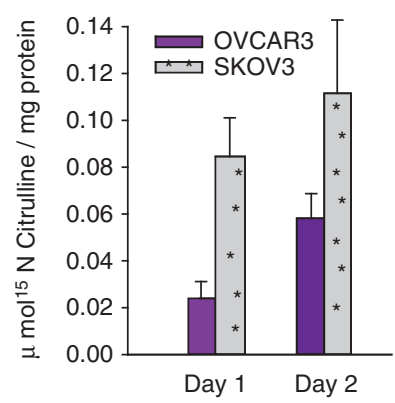

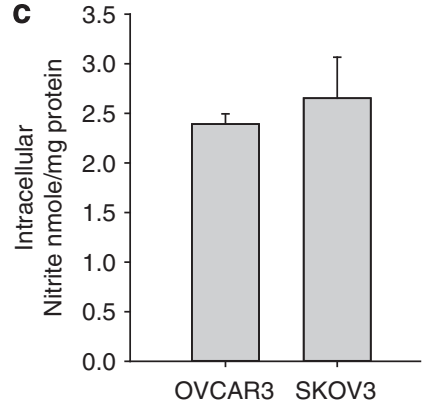
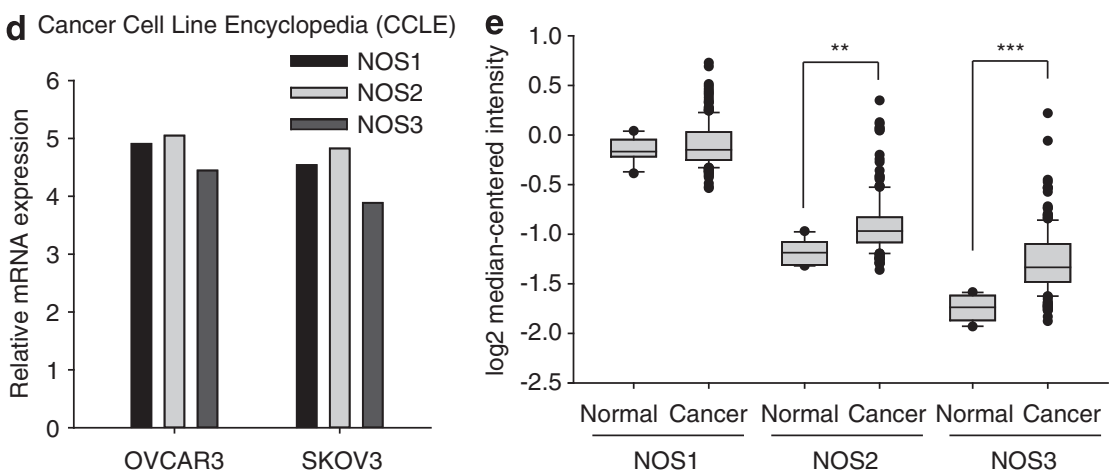

Figure 1 Arginine's conversion to NO and citrulline through NOS found to be active in OVCA cells. (a) Hypothesized pathway for conversion of arginine to NO and citrulline in OVCA cells. (b) Pathway was shown to be active using liquid chromatography-mass spectroscopy (LC-MS). Cells were cultured in RPMI containing $10 \%$ guanido- ${ }^{15} \mathrm{~N}_{2}$ arginine enrichment. LC-MS results revealed that OVCA cells produced citrulline from arginine, indicating NO pathway activity. $n=9$. (c) Intracellular nitrite concentration measured in OVCAR3 and SKOV3 using Griess assay. $n \geq 3$. (d) NOS1, NOS2, and NOS3 mRNA expression levels obtained from CCLE data set for SKOV3 and OVCAR3 cell lines. (e) Comparison of NOS1, NOS2 and NOS3 expression levels between normal ovarian surface epithelial cells and OVCA cells. Data were downloaded from Bonome Ovarian data set

NO affects the proliferation and colony formation, as well as anoikis resistance of OVCA cells. Arginine is converted by NOS to NO and citrulline. Previous research has shown that NO may positively or negatively affect tumor growth based on the conditions tested. ${ }^{3,11}$ As arginine is a main source of $\mathrm{NO}$ in cells, we sought to deprive the cells of arginine over the course of 4 days and measure cell proliferation to determine whether NO has a pro- or anti-tumorigenic role in OVCA. We found that arginine deprivation decreases proliferation in both OVCA cell lines (Figure 2a). Additionally, this decrease in proliferation was found to be paired with a decrease in citrulline secretion
(Figure 2b). Moreover, addition of Deta-NONOate, a NO donor, marginally decreased citrulline secretion from OVCA cells. Additionally, cells were treated with NOS inhibitor, L-NAME, at different concentrations, and proliferation was measured over the course of 3 days. Results showed that L-NAME decreased OVCA cell proliferation in a dosedependent manner for two OVCA cells (Figure 2c). To understand the concentration-dependent role of $\mathrm{NO}$ on OVCA cells, we measured proliferation of SKOV3 cells at varying concentrations of SNAP and Deta-NONOate. Our data clearly illustrate that low SNAP/Deta-NONOate concentrations (20-2000 nM) supported cancer growth. 
a

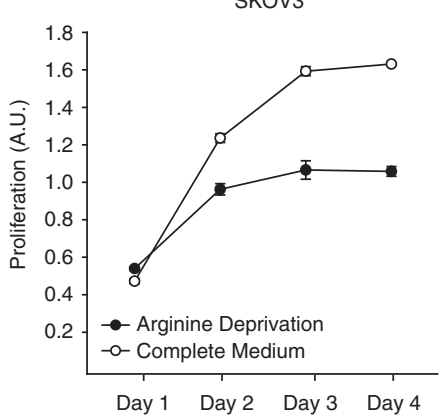

C

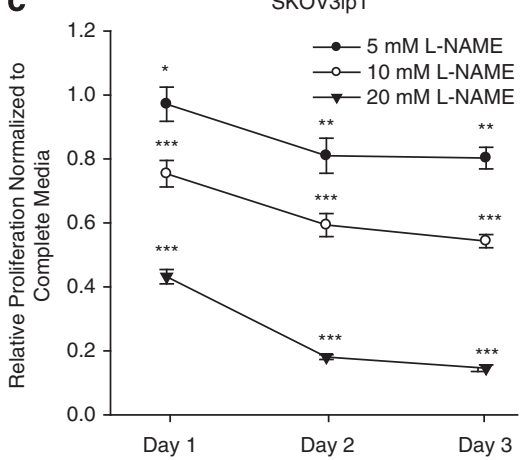

d

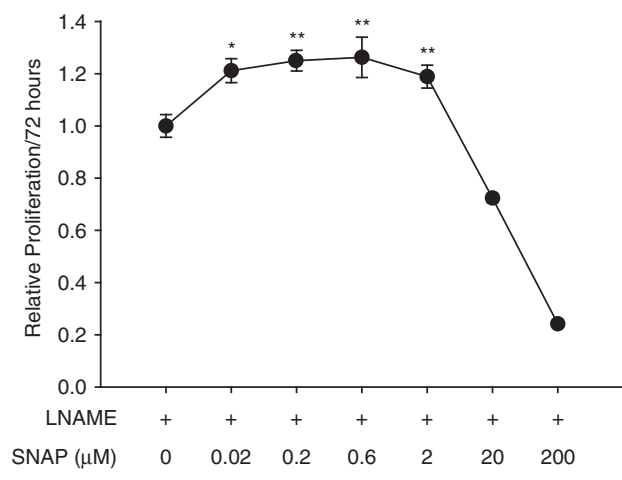

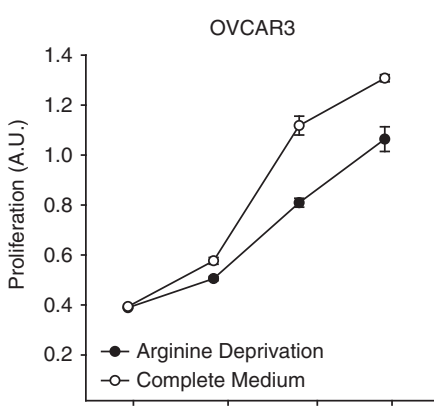

Day 1 Day 2 Day 3 Day4

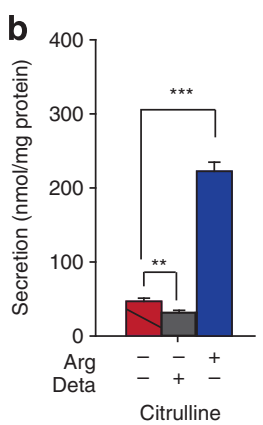

OVCAR3

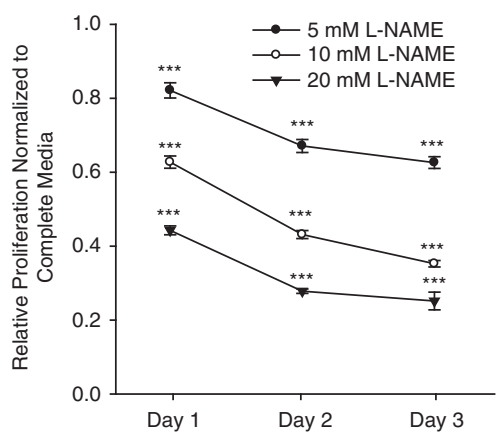

SKOV3

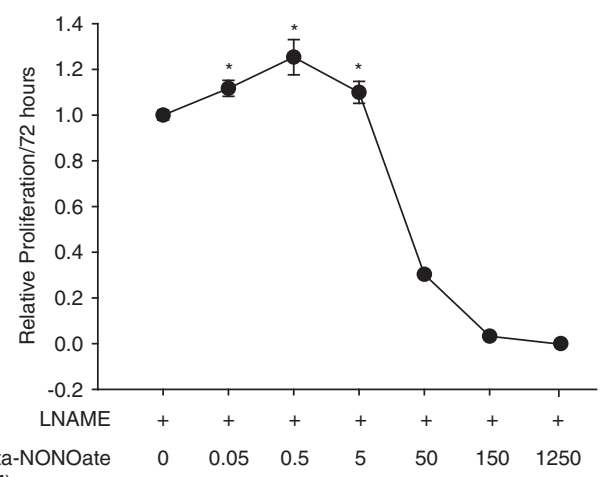
$(\mu \mathrm{M})$
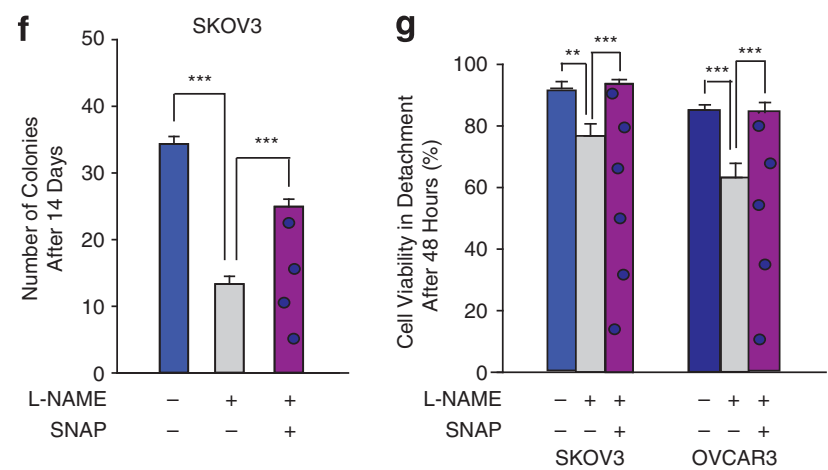

Figure 2 NO affected colony formation and proliferation of OVCA cells. (a) Arginine deprivation decreased the proliferation of OVCA cells, OVCAR3 and SKOV3 over the course of 4 days. (b) Arginine increased citrulline secretion for SKOV3 and OVCAR3. Citrulline was measured using UPLC. (c) L-NAME decreased the proliferation of OVCAR3 and SKOV3 in a dose-dependent manner. (d) Effect of varying concentrations of SNAP on the growth rate of SKOV3. (e) Effect of varying concentrations of DETA-NONOate on the growth rate of SKOV3. (f) Soft agar clonogenic assay showed that L-NAME, an inhibitor of NOS, decreased colony formation of SKOV3 OVCA cells and that $500 \mathrm{nM}$ SNAP, a NO donor, rescued the decrease in colony formation. (g) L-NAME decreased cell viability in detached conditions in $48 \mathrm{~h}$, and viability was rescued using NO donor SNAP. Data are expressed as mean \pm S.E.M. $\left({ }^{*} P<0.05 ;{ }^{* *} P<0.01\right.$; and $\left.{ }^{* * *} P<0.001\right), n=9$ 
However, higher SNAP/Deta-NONOate concentrations $(>20 \mu \mathrm{M})$ had inhibitory effect on cell proliferation (Figure $2 \mathrm{~d}$ and e). Consistent with above results, L-NAME decreased colony formation in a dose-dependent manner of SKOV3ip1 OVCA cells in soft agar (Figure 2f). Interestingly, when OVCA cells were cultured in low attachment plates mimicking detached state with L-NAME, cell viability decreased (Figure $2 \mathrm{~g}$ ). This decrease in viability was rescued by addition of $\mathrm{NO}$ donor SNAP, indicating that NO maintains anoikis resistance (an ability of cancer cells to survive without extracellular matrix) in OVCA cells. Our results demonstrate that $\mathrm{NO}$, at low concentrations, increased OVCA cell proliferation, colony formation, and anoikis resistance, while high concentrations of $\mathrm{NO}$ reduced OVCA cell proliferation.

$\mathrm{NO}$ is involved in maintaining high glycolytic rate in OVCA cells through increased hexokinase 2 expression. We next hypothesized that NO's modulation of proliferation and anoikis resistance of OVCA cells occurred as a result of upregulated glycolysis. Our results show that when NO production is decreased through exposure to L-NAME, glucose consumption and lactate production decreased compared with without L-NAME addition (Figure 3a). Through probing the intracellular lactate concentration in cancer cells by GC-MS, we confirmed the result that L-NAME addition decreases pyruvate's conversion into lactate in OVCA cells (Figure 3b). Therefore, inhibiting NO generation indeed decreased the glycolytic rate of cancer cells. Thus, NO may be responsible for regulating the Warburg effect in OVCA cells. As hexokinase 2 is the ratelimiting enzyme in glycolysis, we hypothesized that $\mathrm{NO}$ maintained high glycolytic rates in OVCA cells through increased hexokinase 2 expression. Our results revealed that $\mathrm{NO}$ increased hexokinase2 expression (Figure 3c). Therefore, NO can maintain high glycolytic rates in OVCA cells by increased hexokinase2 expression.

As our results showed that with L-NAME the glycolytic rate decreased compared with without L-NAME in the OVCA cells, we then hypothesized that when $\mathrm{NO}$ is added, glucose consumption and lactate secretion would increase. Our results showed that when DETA-NONOate was added, there was an increase in glucose consumption and lactate secretion compared with without DETA-NONOate (Figure 3d), further suggesting that $\mathrm{NO}$ may have a role in positively regulating glycolytic rates in cells. In agreement with glucose and lactate secretomics-based assays, GC-MS results also indicated that adding DETA-NONOate led to an increase in pyruvate and lactate concentration in OVCA cells (Figure 3e), thereby directly demonstrating NO's role in enhancing glycolysis fluxes in OVCA cells. Interestingly, pyruvate uptake was decreased in the presence of $\mathrm{NO}$, which might be because of NO-induced reduced mitochondrial TCA cycle activity (Figure $3 \mathrm{f}$ ).

NO decreases oxygen consumption by decreasing mitochondrial complex II + III and complex IV activities but does not significantly decrease ATP production in OVCA cells. The above experiments show that $\mathrm{NO}$ is important for glycolysis of OVCA cells. We further investigated whether NO modulates mitochondrial activity of cancer cells. We hypothesized that NO would affect the oxygen consumption rate of OVCA cells. Our results showed that exposure of cells to DETA-NONOate under arginine deprivation decreased the oxygen consumption, including basal oxygen consumption and ATP-linked oxygen consumption of both OVCA cell lines and reserve capacity in OVCAR3 cells, thus indicating that $\mathrm{NO}$ decreases OXPHOS activity in OVCA cells (Figure 4a). NO also reduced the respiratory capacity ratio, implying mitochondrial's capacity for substrate oxidation, thereby suggesting that $\mathrm{NO}$ could modulate the mitochondrial function in OVCA cells (Figure 4a). DETANONOate did not significantly affect proton leak, indicating that NO has no affect on mitochondrial integrity (Figure 4a).

As NO has been shown to inhibit COX in normal cells, we hypothesized that the decrease in oxygen consumption in OVCA cells by DETA-NONOate was through inhibition of complex II+ III and complex IV of the mitochondria. Our results showed that depriving cells of arginine increased complex II + III and IV activity and that the activities with DETA-NONOate addition were similar to the activities of the arginine-containing media (Figures $4 b-c$ ). Additionally, DETA-NONOate decreased the mRNA levels of the mitochondrial COX1 and cytochrome $b$ (CYTB) (Figure 4d). These findings indicated that NO inhibited oxygen consumption in OVCA cells by inhibiting mitochondrial complex activity and their production at the mRNA level.

Taken together, these results suggest that in the presence of $\mathrm{NO}$ cancer cells underwent high glycolytic rates in order to compensate for the decrease in mitochondrial respiration. In order to explore this further, the effect of NO on ATP production was determined (Figures $4 \mathrm{e}-\mathrm{f}$ ). Under arginine deprivation, and in the presence of DETA-NONOate, OVCA cells did not display a significant decrease in ATP production compared with without DETA-NONOate (Figure 4e). Interestingly, when 2-deoxyglucose, a glucose analog that inhibits glycolysis, was added along with DETA-NONOate, ATP production decreased significantly compared with without DETA-NONOate (Figure 4f). Taken together, these results implicate that NO may positively regulate glycolysis for bioenergetic demand. Further, we demonstrate that, while $\mathrm{NO}$ decreased mitochondrial respiration in OVCA cells, total ATP production was not significantly reduced because of shift in ATP generation from OXPHOS to glycolysis.

NO decouples TCA cycle flux and OXPHOS by enhancing glutaminolysis and reductive carboxylation. The above data demonstrate that NO can inhibit mitochondrial enzyme activity and respiration. To further substantiate the NO's effects on TCA cycle metabolite pools and abundances and activity, we performed ${ }^{13} \mathrm{C}$ GC-MS-based isotope tracer analysis by culturing OVCA cells with labeled $\mathrm{U}^{13} \mathrm{C}_{5} \mathrm{GIn}$ in RPMI medium for $24 \mathrm{~h}$ (Figure 5a). The isotopomer analysis can reveal contribution of a substrate in a particular metabolic pathway. As seen in figure 5a, M5 glutamine (all five glutamine carbons are labeled) entering the TCA cycle is converted into M5 glutamate and M5 alpha-ketoglutarate through glutaminolysis and that alpha-ketoglutarate is further converted into M4 succinate through decarboxylation or M5 citrate through reductive carboxylation (Figure $5 \mathrm{a}$ ). Thus, contribution of glutamine to TCA cycle metabolite pools is 
a

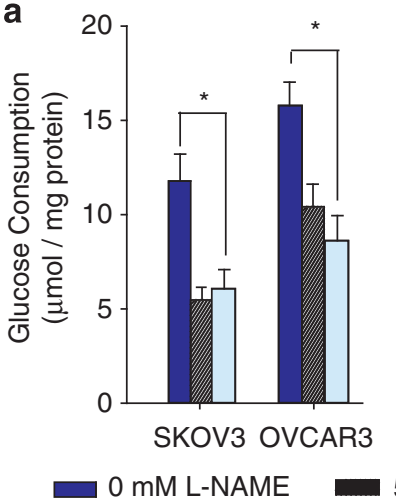

C

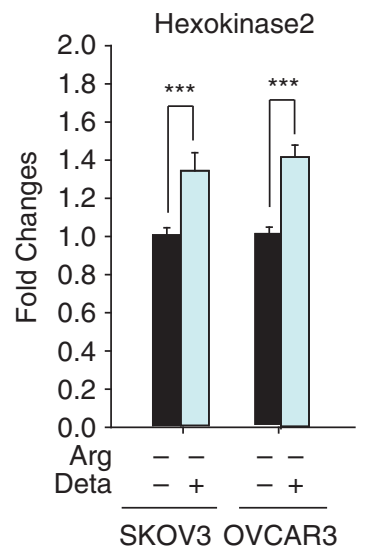

e

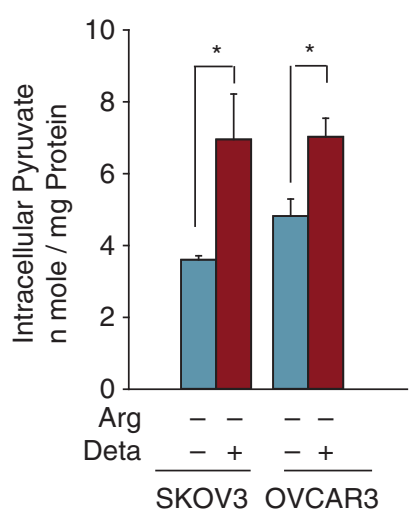

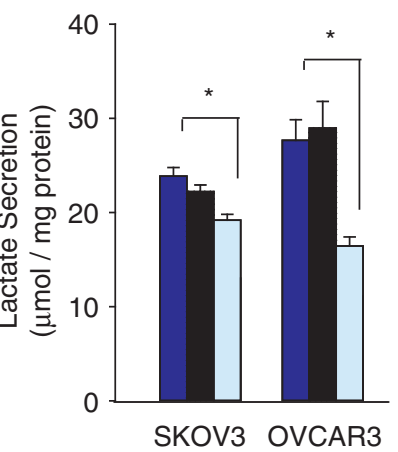

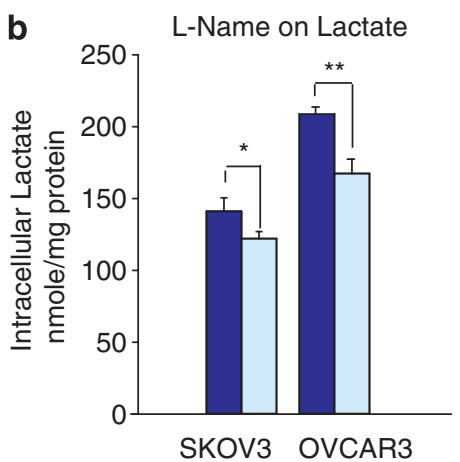

5 mM L-NAME $\square 10 \mathrm{mM} \mathrm{L-NAME}$
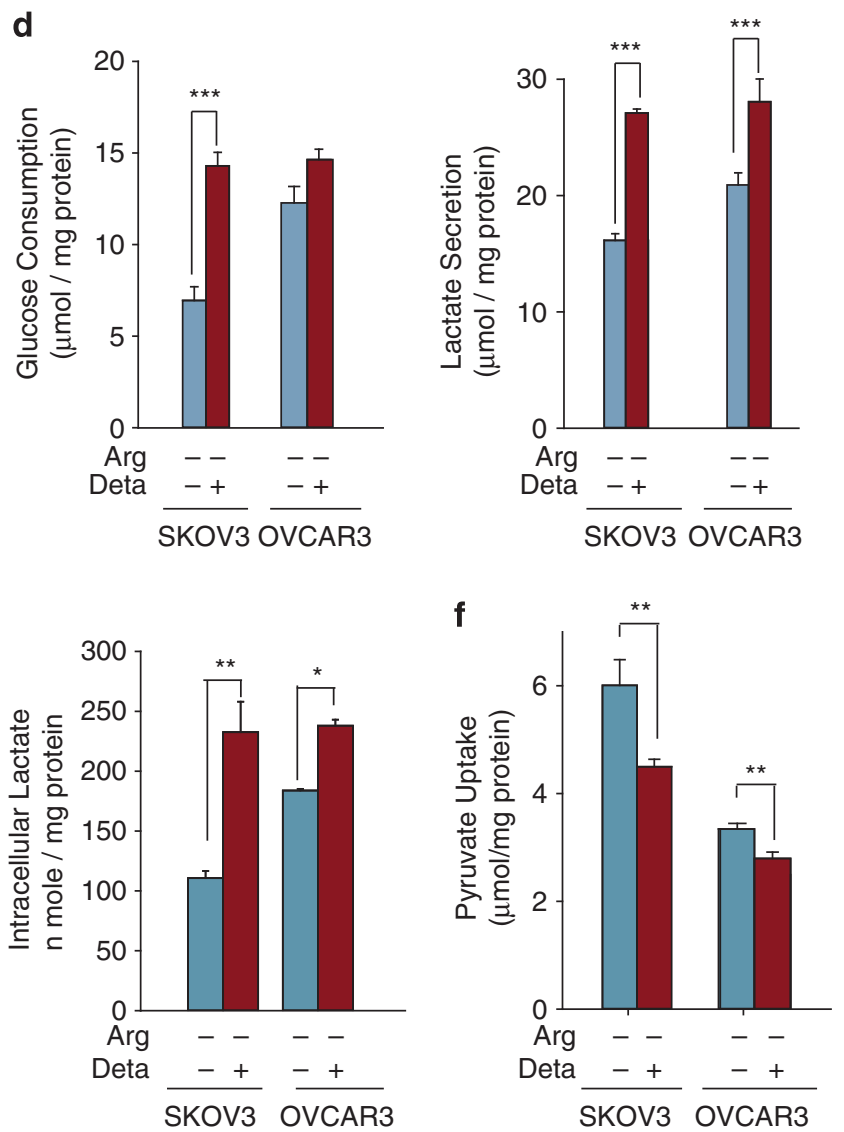

Figure 3 NO had a role in maintaining glycolytic rate in OVCA cells. (a) L-NAME decreased glucose uptake and lactate secretion of SKOV3 and OVCAR3 cells compared with without L-NAME. (b) L-NAME decreased intracellular lactate concentration using gas chromatography-mass spectrometry (GC-MS). (c) Hexokinase2 expression increased with $100 \mu \mathrm{M}$ DETA-NONOate compared with without DETA-NONOate, as measured using qPCR, suggesting that NO may maintain glycolytic rate by increasing hexokinase2 expression. (d) OVCA cells were cultured for $24 \mathrm{~h}$ to measure the glucose uptake and lactate secretion measurements, with and without DETA-NONOate. (e) Using GC-MS, intracellular pyruvate and lactate concentration were measured in OVCA cell cultures with and without DETA-NONOate. (f) Pyruvate uptake was measured using the standard colorimetric assays, which indicated that DETA-NONOate decreased pyruvate uptake. Data are expressed as mean \pm S.E.M. $\left({ }^{\star} P<0.05 ;{ }^{*} P<0.01\right.$; and $\left.{ }^{* * \star} P<0.001\right), n=9$

estimated using labeled $\mathrm{U}-{ }^{13} \mathrm{C}_{5}$ GIn through its conversion to M5 glutamate, M4 fumarate, M4 malate, and M4 citrate levels.

Surprisingly, our results suggested that TCA cycle activity was enhanced in the presence of NO. NO is found to increase the total citrate accumulated and alpha-ketoglutarate, succinate, and fumarate in SKOV3, which suggested that NO increased TCA cycle activity in SKOV3. For OVCAR3, even though NO did not result in significant changes in amounts of many metabolites, citrate was dramatically accumulated (Figure 5b). From the metabolites isotopomer distribution (MID) of citrate, M4, M5, and M6 citrate, derived from glutamine, were enhanced (Figures $5 \mathrm{e}$ and f). Therefore, when NO was present and oxidative phosphorylation (OXPHOS) was inhibited, cancer cells tended to use glutamine as a source to maintain the TCA cycle to meet the requirement of cell proliferation. 

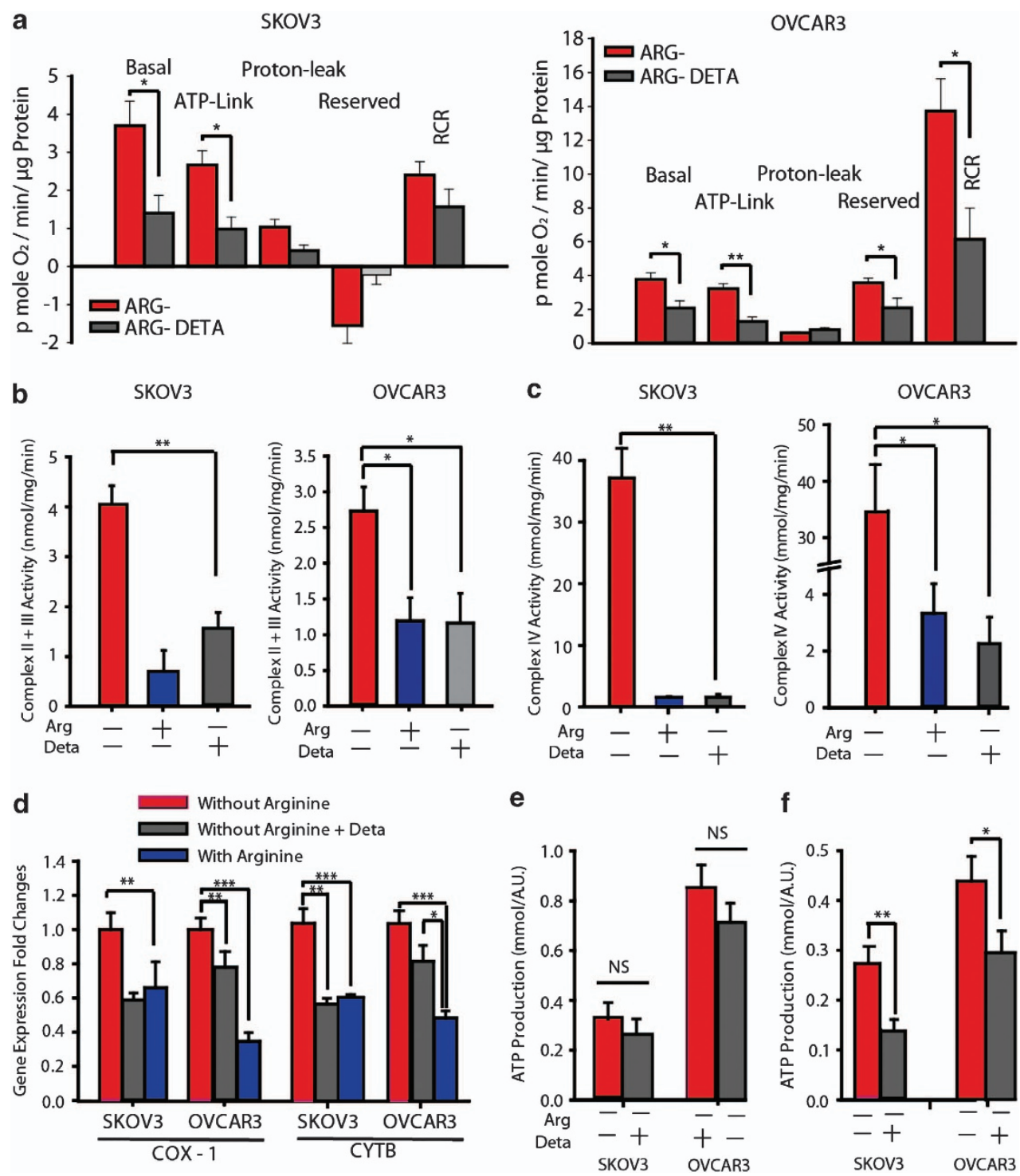

Figure 4 NO impaired mitochondrial respiration and altered source of ATP in OVCA cells. (a) DETA-NONOate decreased oxygen consumption rate (OCR) in OVCA cells SKOV3 and OVCAR3. In particular, DETA-NONOate decreased basal and ATP-linked OCR for both OVCAR3 and SKOV3. (b) NO in the form of both DETA-NONOate and arginine, decreased complex II + III activity, compared with without arginine or NO. (c) Similarly, NO in the form of DETA-NONOate and arginine, decreased complex IV activity in the mitochondria, compared with without arginine or NO. (d) NO decreased gene expression of COX-1 and CYTB for SKOV3 and OVCAR3, as shown by qPCR. (e) ATP production was maintained in the presence of DETA-NONOate. (f) ATP production was decreased by DETA-NONOate when glycolysis was inhibited by 2-DG. Data are expressed as mean \pm S.E.M. (NS, not significant; ${ }^{*} P<0.05 ;{ }^{* *} P<0.01$; and ${ }^{* *} P<0.001$ ), $n=9$

NO can increase the glutamine concentration and its conversion into glutamate and alpha-ketoglutarate in both OVCA cells. Our results showed that NO also increased M4 succinate, fumarate, malate, and citrate through TCA cycle (Figure 5e). Furthermore, NO increased M6 citrate through malic enzyme, which converted M4 malate into M3 pyruvate along with generation of NADPH. M3 pyruvate was further catalyzed into M2 acetyl-CoA, which condensed with M4 oxaloacetate (Figures 5a and e). Concomitantly, OVCA cells also enhanced citrate generation through direct conversion of alpha-ketoglutarate through reductive carboxylation to generate M5 citrate (Figure 5f). Taken together, our results showed that NO could enhance glutaminolysis and reductive carboxylation to meet the requirement of proliferating OVCA cells.
NO contributes to NADPH production, and decreases ROS production in OVCA cells. Having established that $\mathrm{NO}$ increases glutaminolysis, we aimed to determine whether NO could decrease ROS levels through glutamine. Glutamine can be used to create glutathione, an antioxidant, to decrease ROS levels and produce NADPH through malic enzyme. ROS can potentially cause cancer cell death or aid in the development of cancer ${ }^{46-49}$ and may be a mechanism by which $\mathrm{NO}$ enhances colony formation and anoikis resistance. Our results showed that ROS production increased significantly with exposure to L-NAME in a dosedependent manner (Figure 6a). Additionally, exposure to DETA-NONOate along with L-NAME resulted in less ROS production compared with L-NAME without DETA-NONOate 

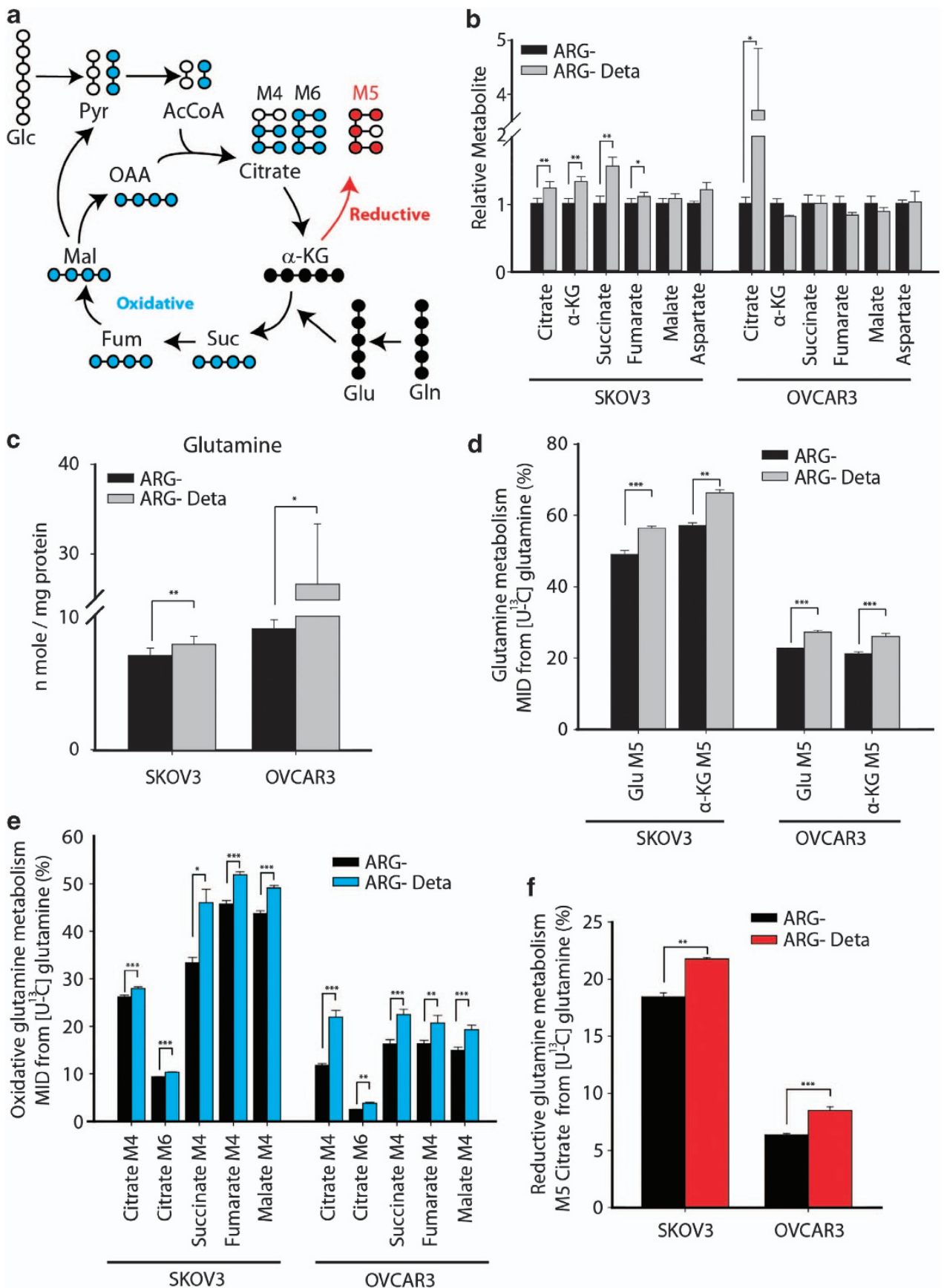

Figure 5 NO decoupled TCA cycle flux and OXPHOS by enhancing glutaminolysis and reductive carboxylation. (a) U- ${ }^{13} \mathrm{C}_{5}$ glutamine's conversion into TCA cycle metabolites through oxidative TCA cycle and reductive carboxylation. (b) Relative metabolites abundance for OVCAR3 and SKOV3 showed increase in citrate, alphaketoglutarate, succinate, and fumarate with DETA-NONOate for SKOV3 as well as increase in citrate with DETA-NONOate for OVCAR3. (c) NO increased glutamine concentration in SKOV3 and OVCAR3. (d) NO increased M5 glutamate and M5 alpha-ketoglutarate, which is directly derived from M5 glutamine. (e) NO increased oxidative glutamine metabolism indicated from M4, M6 citrate, M4 succinate, M4 fumarate, M4 malate, as well as reductive glutamine metabolism (f), indicated from M5 citrate. Data are expressed as mean \pm S.E.M. $\left({ }^{*} P<0.05 ;{ }^{* *} P<0.01 ;\right.$ and $\left.{ }^{* *} P<0.001\right), n=9$

(Figures $6 b-c)$. These results indicated that NO decreased ROS production in OVCA cells, thus maintaining redox balance and viability.

NADPH is an important antioxidant regulating ROS level in cells and is produced mainly from PPP pathway and malic enzyme activity. To assess whether NO induced increased glucose uptake and glutaminolysis increased
NADPH generation, we measured NADPH for a variety of OVCA cell lines. Our results showed that NADPH production decreased with addition of L-NAME in a dose-dependent manner for all the cell lines tested and that addition of DETA-NONOate increased NADPH production compared with without DETA-NONOate (Figures $6 \mathrm{~d}-\mathrm{e}$ ). Our results suggest that the decrease in ROS production by NO could be 

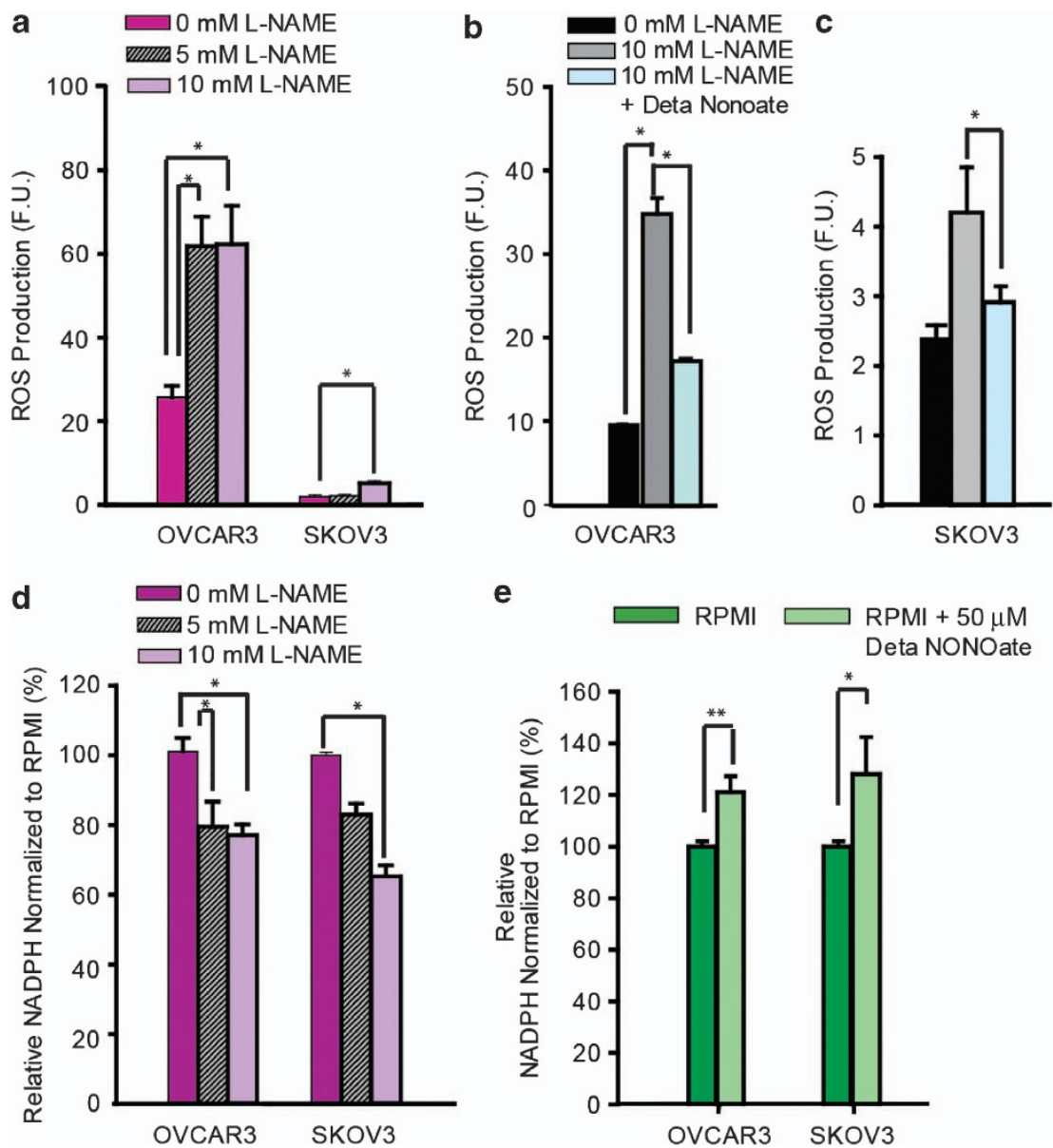

Figure 6 NO maintained glycolysis and antioxidant production. (a) L-NAME increased ROS production. (b and c) DETA-NONOate rescued L-NAME's effect on ROS production. (d) L-NAME decreased NADPH production. (e) DETA-NONOate increased NADPH production in OVCA cells. Data in panels (a-d) are expressed as mean \pm S.E.M. $\left({ }^{*} P<0.05\right)$, and one-way ANOVA with Dunn's and Dunnett post hoc tests were used to compare conditions, $n=9$. Data in panel e are expressed in mean \pm S.E.M. $\left({ }^{\star} P<0.05 ;{ }^{* *} P<0.01\right.$; and $\left.{ }^{* \star *} P<0.001\right)$, and $t$-test was used to compare conditions, $n=8$

due to an increase in NADPH levels and antioxidant production.

\section{Discussion}

It has been shown that NO, an unstable gas, can have effects on the growth and proliferation of cancer cells, either inhibiting or enhancing growth depending on the NO concentration and extracellular conditions. ${ }^{3,11,14,15} \mathrm{NO}$ has also been linked to metastasis in a recent study that suggest that iNOS expression correlated to the upregulation of the Wnt pathway. ${ }^{50}$ These studies suggest that NO may have a central role in tumor growth and progression of cancer cells. However, the comprehensive role of $\mathrm{NO}$ in OVCA cell metabolism, specifically how NO affects glycolysis and TCA cycle flux in OVCA cells and finally ROS production, is lacking. We show in this study that NO decreases mitochondrial respiration and shift these cells towards maintaining high glycolytic rates in order to avoid a decrease in ATP production. Thus we have found that $\mathrm{NO}$ is important in maintaining the Warburg effect of OVCA cells. Also, our results are the first to show that NO may be increasing TCA cycle flux, which may lead to production of antioxidants to combat cellular ROS.
It is known that arginine is converted to NO by NOS, as depicted in Figure 1a. OVCA cells have been shown to express ASS and thus are capable of de novo arginine production when deprived of arginine. ${ }^{23}$ However, we show that arginine deprivation decreases proliferation of OVCA cells over a period of 4 days. This suggests that, although OVCA cells may be able to make their own arginine through ASS, they cannot produce enough arginine to support proliferation of cells over long time periods and will, therefore, require exogenous arginine to sustain proliferation. Glutamine has been shown to be a potential source of arginine and NO synthesis in murine macrophages, ${ }^{51}$ although research involving the production of arginine from other amino acids and metabolites in cancer cells is lacking. The fact that OVCA cells cannot continue proliferation without exogenous arginine renders them susceptible to arginine deprivation and to depletion therapies. Arginine deiminase (ADI) was first isolated from bacteria Pseudomonas putida ${ }^{52}$ and can deplete arginine from the blood and induce arginine deprivation. ${ }^{53}$ Pegylated ADI (ADI PEG-20) has been shown to be effective in inhibiting small cell lung cancer growth, ${ }^{53}$ inducing autophagy and caspase-independent apoptosis in PC3 prostate cancer cells, ${ }^{54}$ and melanoma cells. ${ }^{55}$ As the 
effectiveness of the drug was dependent on the lack of ASS expression in these cells, further studies must be conducted to determine whether ADI PEG-20 can be effective in OVCA over longer periods of time.

It has also been shown that NO can bind to COX in the mitochondria, in competition with oxygen ${ }^{56}$ and thus can decrease oxygen consumption rate. ${ }^{37}$ However, through analysis of glycolytic flux and ATP production, our data suggest that glycolysis is increased in OVCA cells in order to maintain ATP production in response to the inhibition of mitochondrial respiration. Additionally, our study is one of the first to suggest that, by maintaining glycolytic flux, NO could in turn lead to an increase in NADPH production through PPP and glutaminolysis, thus affecting ROS production.

Our results further suggest that NO increases TCA cycle flux through not only increase in glucose uptake but also increase in cellular glutamine. Our findings suggest a potential link between the TCA cycle and NO in cancer cells. This increase in TCA cycle activity may result in the production of glutathione, an antioxidant used by cancer cells to combat ROS. ROS and NO have been studied together in the context of several cancers. ${ }^{4,57,58}$ However, a metabolic connection linking the two has not yet been fully elucidated. Our results suggest that NO increases glutamine uptake, further implying that NO may increase glutathione and NADPH production, which could be used to reduce ROS levels in OVCA cells.

In conclusion, our findings have shown that $\mathrm{NO}$ has a central role in the metabolism of OVCA cells by (i) inhibiting mitochondrial respiration, which can in turn force OVCA cells to maintain high glycolytic rates, (ii) enhancing proliferation, and (iii) maintaining low ROS levels. In addition, NO increases TCA cycle flux and glutaminolysis, which may lead to increases in glutathione levels, thus further maintaining low ROS levels.

\section{Materials and Methods \\ Cells and media. OVCA cells, OVCAR3 and SKOV3, were purchased from ATCC (Manassas, VA, USA) on behalf of Rice University, Houston, TX, USA. SKOV3ip1 cells were kindly provided by Dr. Anil Sood of MD Anderson Cancer Center. Cells were grown in RPMI 1640 (Gibco, Grand Island, NY, USA) containing $10 \%$ fetal bovine serum. Cells used in these experiments were cultured below 75 passages.}

LC-MS experiments. OVCA cells were seeded at $90000 \mathrm{cells} / \mathrm{ml}$ in a 12-well plate. After $24 \mathrm{~h}$, media was changed to phenol red-free RPMI medium containing $\left[{ }^{15} \mathrm{~N} 2\right]$ arginine at a $10 \%$ enrichment. After $48 \mathrm{~h}$, media was collected and analyzed for the presence of $\left[{ }^{15} \mathrm{~N}\right]$ citrulline using LC-MS. Protein was collected and later analyzed with Pierce BCA Protein Kit (Thermo Scientific, Rockford, IL, USA) for normalization.

Endogenous NO measurements. OVCA cells were seeded in T-75 flasks. After the cells were around $80 \%$ confluency, media was replaced. After $24 \mathrm{~h}$, cells were washed in PBS solution at $4{ }^{\circ} \mathrm{C}$, trypsinized and collected into $1.5-\mathrm{ml}$ tubes. Cell pellets were lysed in PBS solution containing $1 \%$ Nonidet P- 40 , $2 \mathrm{mM} \mathrm{N}$-ethylmaleimide, $0.2 \mathrm{mM}$ diethylenetriaminepentaacetic dianhydride, and protease inhibitors. After three instant freeze/thaw cycles, lysates were centrifuged at 6000 r.p.m. for $10 \mathrm{~min}$ at $4{ }^{\circ} \mathrm{C}$. Protein concentrations were determined in supernatant by Pierce BCA protein assay (Thermo Scientific), and nitrite assays was determined through Griess assay.

Proliferation assay. Proliferation of OVCA cells was measured using Cell Counting Kit-8 (Dojindo Molecular Technologies, Inc., Rockville, MD, USA). Briefly, cells were seeded in a 96-well plate between 10000 and 50000 cells/ml. After 24, 48,72 , or $120 \mathrm{~h}, 10 \mu \mathrm{l}$ of kit reagent was added to each well. Plate was then shaken and incubated for $2 \mathrm{~h}$ before reading the absorbance in a spectrophotometer (SpectraMax M5 from Molecular Devices, Sunnyvale, CA, USA) at $450 \mathrm{~nm}$.

Soft agarose colony formation. Bottom agarose solution (10\%) was created by dissolving agarose in hot water and placing it in the waterbath to cool the solution to $37^{\circ} \mathrm{C}$. Agarose was then mixed in a $1: 1$ ratio with 2x RPMI, and $1.5 \mathrm{ml}$ of this solution was used to coat each well of a six-well plate. Plate was left under hood for $30 \mathrm{~min}$ in order to allow agarose to solidify before adding cells and top agarose. Top agar solution (70\%) was created by again dissolving agarose in hot water and placing it in the waterbath to cool the solution to $37^{\circ} \mathrm{C}$. Cells were then harvested, counted, and resuspended at a concentration of $200000-$ $400000 \mathrm{cells} / \mathrm{ml}$. Next, $3 \mathrm{ml}$ of top agarose was mixed with $3 \mathrm{ml}$ of warm 2x RPMl, $0.1 \mathrm{ml}$ of cell suspension was added, and $1.5 \mathrm{ml}$ of the mixture was added to each of a six-well plate already coated with bottom agarose. Cells were then fed with $0.5 \mathrm{ml}$ of media every 3 days and kept in culture for 14 days. Cells were then stained with a $0.5-\mathrm{ml}$ crystal violet $(0.005 \%$ in methanol) solution, and colonies were counted using a $4 \times$ objective. Four fields of view of each well were imaged and analyzed.

Arginine-deprivation experiments. Cells were seeded in a 96-well plate at a density between 10000 and $30000 \mathrm{cell} / \mathrm{s} / \mathrm{ml}$ in complete RPMI 1640 media. Approximately $24 \mathrm{~h}$ after seeding, media was changed to RPMI without arginine (Sigma Aldrich, Madison, WI, USA) or phenol red-free RPMI-1640 containing arginine (Gibco). After 24, 48, 72, and $120 \mathrm{~h}$, plates were assessed using Cell Counting Kit-8 (Dojindo Molecular Technologies, Inc.), as mentioned above. Media was changed every $48 \mathrm{~h}$ for the remaining plates at each time point.

Metabolic assays. Glucose consumption assay was performed using the Wako Glucose Kit (Wako Chemicals, Richmond, VA, USA) according to the manufacturer's protocol. Briefly, $2 \mu \mathrm{l}$ sample and $250 \mu \mathrm{l}$ reconstituted Wako glucose reagent was added to a 96-well assay plate and incubated while shaking at $37^{\circ} \mathrm{C}$ for $5 \mathrm{~min}$. The change in absorbance, indicating the presence of glucose, was measured at $505 \mathrm{~nm}$ by using a spectrophotometer (SpectraMax M5 from Molecular Devices). Lactate secretion was determined using the Trinity Lactate Kit (Trinity Biotech, Jamestown, NY, USA) according to the manufacturer's protocol. Briefly, lactate reagent was reconstituted with $10 \mathrm{ml}$ milliohm water and diluted $1: 4$ in $0.1 \mathrm{M}$ Tris Solution $(\mathrm{pH}=7.0)$. Media samples were diluted $1: 10$ in PBS, and lactate reagent was added to the diluted samples in an assay plate. The plate was protected from light and incubated for $1 \mathrm{~h}$ before reading the change in absorbance on a spectrophotometer at $540 \mathrm{~nm}$. The pyruvate assay used measures the amount of sodium dehydrogenase (NADH) oxidized, which correlates with the amount of pyruvate in the samples. Pyruvate uptake analysis was performed using the following protocol. Briefly, NADH solution was created by reconstituting NADH powder (Sigma Aldrich) in $50 \mathrm{ml}$ Tris solution $(\mathrm{pH}=7.0)$. Lactate dehydrogenase (LDH) was reconstituted in $50 \%$ glycerol and diluted $1: 20$ in Tris solution $(\mathrm{pH}=7.0)$. In a 96-well plate, $20 \mu \mathrm{l}$ of sample was added to each well along with the NADH reagent. A prereading was taken at $340 \mathrm{~nm}$ in a spectrophotometer, and LDH was added to the wells. Plate was incubated for $1 \mathrm{~h}$ without carbon dioxide, and subsequent measurements were taken on a spectrophotometer.

Stable isotope analysis using GC-MS. OVCA cells were cultured with $13 \mathrm{C}_{5}$ Gln-labeled arginine-free RPMI medium (without/with $100 \mu \mathrm{M}$ DETA NONOate) in six-well plates for $24 \mathrm{~h}$. Medium was aspirated, and cells were quenched with $0.4 \mathrm{ml}-20 \%$ methanol, and $0.4 \mathrm{ml}$ ice autoclaved water containing $1 \mu \mathrm{g}$ norvaline internal standard was added. Then, cells were collected by scraping with a cell scraper. Then, $0.8 \mathrm{ml}$ chloroform was added and vortexed at $4{ }^{\circ} \mathrm{C}$ for $30 \mathrm{~min}$. Samples were centrifuged at $3000 \times \mathrm{g}$ for $15 \mathrm{~min}$ at $4{ }^{\circ} \mathrm{C}$. In parallel, protein levels in six-well plates were measured to normalize the metabolite levels in cells. Dried samples were dissolved in $30 \mu \mathrm{l}$ of $2 \%$ methoxyamine hydrochloride in pyridine (Pierce), sonicated for $30 \mathrm{~min}$, and held at $37^{\circ} \mathrm{C}$ for $2 \mathrm{~h}$. After the reaction, $45 \mu \mathrm{l}$ MBTSTFA $+1 \%$ TBDMCS (Pierce) was added, and samples were incubated at $55^{\circ} \mathrm{C}$ for $1 \mathrm{~h}$. Tubes were vortexed in between. GC/MS analysis was performed using an Agilent $6890 \mathrm{GC}$ (Agilent Technologies, Santa Clara, CA, USA) equipped with a 30-m DB-35 MS capillary column connected to an Agilent 5975B MS (Agilent Technologies) operating under electron impact ionization at $70 \mathrm{eV}$, and $1 \mu \mathrm{l}$ of the sample was injected in split mode at $270^{\circ} \mathrm{C}$, using helium as the carrier gas at a flow rate of $1 \mathrm{ml} / \mathrm{min}$. The GC oven temperature was held at $100^{\circ} \mathrm{C}$ for $3 \mathrm{~min}$, increased to $250^{\circ} \mathrm{C}$ at $8{ }^{\circ} \mathrm{C} / \mathrm{min}$ and then to $300^{\circ} \mathrm{C}$ at $40^{\circ} \mathrm{C} / \mathrm{min}$ and held for $3 \mathrm{~min}$ for a total run time of $26 \mathrm{~min}$. 
Data were acquired in scan mode. MIDs are obtained for each measured metabolite and incorporated with extracellular flux measurements for flux determination. To determine relative metabolite abundances, the integrated signal of all potentially labeled ions for each metabolite fragment was normalized by the signal from norvaline and the per well cell number (obtained by counting surrogate plates). To determine the MID value, each isotopomer signal is normalized from the sum of isotopomer's signals.

ATP measurement. ATP was measured using the Cell Titer-Glo assay (Promega). Briefly, cells were seeded at a density of 150000 and $60000 \mathrm{cells} / \mathrm{ml}$ in a 96-ell plate. After $48 \mathrm{~h}$ in culture, media was removed, and phenol red-free media containing L-NAME at different concentrations was added to the wells. Cells were incubated for $3 \mathrm{~h}$, and reagent was added ( $100 \mu \mathrm{l}$ per well). Plate was then kept in dark for $10 \mathrm{~min}$ and read in a spectrophotometer in luminescence.

NADPH assay. NADPH assay was modified from the protocol by de Murcia's team in Illkirch, France. ${ }^{59}$ Briefly, stock solutions of XTT (251 mM in DMSO) and 1-methoxy-5-methylphenazinium methylsulfate (PMS, $0.5 \mathrm{mM}$ in DMSO) were prepared. A PMS/XTT solution was then prepared by dissolving $3.2 \mathrm{mI}$ XTT in $66.6 \mu \mathrm{l}$ PMS. Cells were seeded in a 96-well plate at a density of 150000 and $60000 \mathrm{cell} / \mathrm{s} / \mathrm{ml}$. After $48 \mathrm{~h}$ of culture, media was removed, and $100 \mu \mathrm{l}$ of XTT/PMS reagent was added to each well. For rescue experiments, media containing XTT/PMS with or without NO donor DETA NONOate was added to the wells Plates were then incubated and read in a spectrophotometer at $450 \mathrm{~nm}$ with $650 \mathrm{~nm}$ as the reference filter $3 \mathrm{~h}$ after reagent was added.

ROS measurement. Cells were seeded in 96-well plates at densities of $60000-150000 \mathrm{cell} / \mathrm{s} / \mathrm{ml}$. After $48 \mathrm{~h}$, wells were washed with PBS, and media containing H2DCFDA was added to the plate. After 30 min of incubation in dark, plates were washed two times with PBS, and media containing $0,5,10$, or $20 \mathrm{mM}$ L-NAME was added to the wells. For rescue experiments, media containing DETA NONOate along with $10 \mathrm{mM} \mathrm{L-NAME}$ was added to the wells. Plate was then read in fluorescence. Readings were taken up to $3 \mathrm{~h}$ after culture.

Enzymatic activity assay. Complex II/III and complex IV activity were determined according to the protocol used in Long et al. ${ }^{60}$ Cells were cultured to $70 \%$ confluence before harvesting. Cells were then trypsinized and counted to ensure that 3-5 million cells were available for analysis. Cells were then washed twice with $3 \mathrm{ml}$ PBS by centrifuging at $1000 \times g$ for $5 \mathrm{~min}$ and removing the supernatant. Next, $0.4 \mathrm{ml}$ of $20 \mathrm{mM}$ phosphate buffer at $\mathrm{pH}=7.5$ was added to the cells, and cells were mixed with $50-\mu$ l Hamilton syringe. Cells were then snap frozen in liquid nitrogen three times and kept on ice before analysis. Protein was analyzed using the Pierce BCA Protein Kit. To analyze complex II/III, cytochrome $c$ was freshly prepared according to the protocol. A total of $100 \mu \mathrm{l}$ potassium phosphate buffer $(0.5 \mathrm{M}, \mathrm{pH}=7.5), 30 \mu \mathrm{l} \mathrm{KCN}(10 \mathrm{mM}), 25 \mu \mathrm{l}$ succinate $(400 \mathrm{mM})$, and $15-80 \mu \mathrm{g}$ lysate were added to a 1-ml cuvette. Volume of distilled water was then adjusted so that total volume was $950 \mu \mathrm{l}$ water. Cuvette was then inverted to mix and incubated for $10 \mathrm{~min}$ at $37^{\circ} \mathrm{C}$ inside the spectrophotometer. In all, $50 \mu$ l oxidized cytochrome $c$ was then added, and cuvette was inverted to mix. Absorbance at $550 \mathrm{~nm}$ was then monitored every $10 \mathrm{~min}$ for $3 \mathrm{~h}$. Activity was calculated based on the change in absorbance over time. To analyze complex IV, cytochrome $c$ was prepared and reduced using sodium dithionate. Reduced cytochrome $c$, phosphate buffer, water, and cytochrome $c$ were then added to the cuvette according to the protocol. Volume of water was added to adjust volume to $950 \mu \mathrm{l}$. Baseline absorbance was then monitored for $3 \mathrm{~min}$ at $550 \mathrm{~nm}$. Lysate was added to initiate the reaction, and absorbance at $550 \mathrm{~nm}$ was monitored for $3 \mathrm{~min}$. Activity was then calculated based on the change in absorbance over time.

Analysis of gene expression using real-time PCR. SKOV3 and OVCAR3 cells were treated with complete medium, arginine deprivation, or arginine deprivation in combination with $100 \mu \mathrm{M}$ DETA NONOate for $48 \mathrm{~h}$. Total RNA was isolated using an RNeasy mini kit (Qiagen, Valencia, CA, USA). cDNA was synthesized from $1.0 \mu \mathrm{g}$ of total RNA with High Capacity CDNA Reverse Transcription Kit (Applied Biosystems, Foster City, CA, USA) using a Veriti 96-well Thermal Cycler (Applied Biosystems, Foster City, CA, USA). The levels of COX-1, CYTB, HIF1- $\alpha$, and iNOS were examined by real-time PCR using $50 \mathrm{ng}$ of the resultant CDNA. Real-time PCR was performed with the SYBR Green PCR Master Mix (Applied Biosystems, Warrington, UK) using the StepOnePlus Real-Time PCR System (Applied Biosystems, Foster City, CA, USA). Hexokinase II expression was analyzed by real-time PCR using TaqMan assay (Invitrogen, Grand Island, NY, USA). All reactions with COX-1, CYTB, HIF1- $\alpha$, and iNOS were normalized against glyceraldehyde-3-phosphate dehydrogenase (GAPDH) and that of Hexokinase II against beta-actin. Specific primer sets were as follows (listed $5^{\prime}-3^{\prime}$; forward and reverse, respectively): COX-1, TCGCATCTGCTATAGTGGAG and ATTATTCCGAAGCCTGGTAGG; CYTB, TGAAACTTCGGCTCACTCCT and AATGTATGGGATGGCGGATA; HIF1- $\alpha$, ACAGTATTCCAGCAGACTCAA and CCTACTGCTTGAAAAAGTGAA; and iNOS, AGATAAGTGACATAAGT GACC and CATTCTGCTGCTTGCTGAG. Reactions were performed in a volume of $20 \mu \mathrm{l}$ for SYBR Green and $23 \mu \mathrm{l}$ for TaqMan.

OVCA cell microarray. The CCLE OVCA cell line gene expression data set (GSE36133) was downloaded from the Gene Expression Omnibus. Gene expression was normalized relative to the mean expression over all cell line arrays. The expression of NOS1, NOS2, and NOS3 in normal ovarian surface epithelial cells and cancer cells are downloaded from Bonome Ovarian Data set ${ }^{61}$ and analyzed through Oncomine. This data set had 10 normal ovarian surface epithelial cells and 185 OVCA cells derived from OVCA patients.

Statistical analysis. Some statistical analysis was performed using the Student's two-tailed t-test, and this data were reported in all bar graphs as mean \pm S.E.M. In these bar graphs, single asterisk $\left(^{*}\right)$ represents $P \leq 0.05$, double asterisks $\left.{ }^{(* *}\right)$ represent $P \leq 0.01$ and triple asterisks ${ }^{* * *}$ ) represent $P \leq 0.001$. For multiple comparisons, one-way ANOVA with Tukey's, Dunnett, or Dunn's post hoc test was used for statistical analysis. In these graphs, single asterisk ( ${ }^{*}$ ) represents $P \leq 0.05$.

\section{Conflict of Interest}

The authors declare no conflict of interest.

Acknowledgements. This work made possible in part through support from the Ken Kennedy Institute for Information Technology at Rice University, Houston, TX, USA to DN under the Collaborative Advances in Biomedical Computing 2011 seed funding program supported by the John and Ann Doerr Fund for the Computational Biomedicine. This work was supported by Rice University, Houston, TX, USA. We thank Dr Anil Sood (MD Anderson Cancer Center, Houston, TX, USA) for providing OVCA cell line, SKOV3ip1. Additionally, we thank Vidya Subramanian for help with figures. SMH is supported by NIH 1K01DK096093. This work was also partly supported by the Diabetes and Endocrinology Research Center (P30-DK079638) at the Baylor College of Medicine (to SMH).

1. Cannistra SA. Cancer of the ovary. N Engl J Med 2004; 351: 2519-2529.

2. Bast Jr RC, Hennessy B, Mills GB. The biology of ovarian cancer: new opportunities for translation. Nat Rev Cancer 2009; 9: 415-428.

3. Rieder J, Jahnke R, Schloesser M, Seibel M, Czechowski M, Marth C et al. Nitric oxidedependent apoptosis in ovarian carcinoma cell lines. Gynecol Oncol 2001; 82: 172-176.

4. Chowdhury R, Godoy LC, Thiantanawat A, Trudel LJ, Deen WM, Wogan GN. Nitric oxide produced endogenously is responsible for hypoxia-induced HIF-1alpha stabilization in colon carcinoma cells. Chem Res Toxicol 2012; 25: 2194-2202.

5. Raharijaona M, Le Pennec S, Poirier J, Mirebeau-Prunier D, Rouxel C, Jacques C et al PGC-1-related coactivator modulates mitochondrial-nuclear crosstalk through endogenous nitric oxide in a cellular model of oncocytic thyroid tumours. PLoS One 2009; 4: e7964.

6. Nisoli E, Falcone S, Tonello C, Cozzi V, Palomba L, Fiorani M et al. Mitochondrial biogenesis by NO yields functionally active mitochondria in mammals. Proc Natl Acad Sci USA 2004; 101: 16507-16512.

7. Nisoli E, Falcone S, Tonello C, Cozzi V, Palomba L, Fiorani M et al. Mitochondrial biogenesis by NO yields functionally active mitochondria in mammals (Proc Natl Acad Sci USA 2004:101:16507-16512). Erratum in Proc Natl Acad Sci USA 2005; 102: 5635.

8. Le Pennec S, Mirebeau-Prunier D, Boutet-Bouzamondo N, Jacques C, Guillotin D, Lauret $\mathrm{E}$ et al. Nitric oxide and calcium participate in the fine regulation of mitochondrial biogenesis in follicular thyroid carcinoma cells. J Biol Chem 2011; 286: 18229-18239.

9. Nisoli E, Clementi E, Paolucci C, Cozzi V, Tonello C, Sciorati C et al. Mitochondrial biogenesis in mammals: the role of endogenous nitric oxide. Science 2003; 299: 896-899.

10. Sanuphan A, Chunhacha P, Pongrakhananon V, Chanvorachote P. Long-term nitric oxide exposure enhances lung cancer cell migration. Biomed Res Int 2013; 2013: 186972.

11. Pervin S, Singh R, Hernandez E, Wu G, Chaudhuri G. Nitric oxide in physiologic concentrations targets the translational machinery to increase the proliferation of human breast cancer cells: involvement of mammalian target of rapamycin/elF4E pathway. Cancer Res 2007; 67: 289-299. 
12. Cronauer MV, Ince Y, Engers R, Rinnab L, Weidemann W, Suschek CV et al. Nitric oxide-mediated inhibition of androgen receptor activity: possible implications for prostate cancer progression. Oncogene 2007; 26: 1875-1884.

13. Leist M, Single B, Naumann H, Fava E, Simon B, Kuhnle S et al. Inhibition of mitochondrial ATP generation by nitric oxide switches apoptosis to necrosis. Exp Cell Res 1999; 249 396-403.

14. Kisley LR, Barrett BS, Bauer AK, Dwyer-Nield LD, Barthel B, Meyer AM et al. Genetic ablation of inducible nitric oxide synthase decreases mouse lung tumorigenesis. Cancer Res 2002; 62: 6850-6856.

15. Aguilar-Melero P, Ferrin G, Muntane J. Effects of nitric oxide synthase-3 overexpression on post-translational modifications and cell survival in HepG2 cells. J Proteomics 2012; 75 : 740-755.

16. Simeone AM, Broemeling LD, Rosenblum J, Tari AM. HER2/neu reduces the apoptotic effects of $\mathrm{N}$-(4-hydroxyphenyl)retinamide (4-HPR) in breast cancer cells by decreasing nitric oxide production. Oncogene 2003; 22: 6739-6747.

17. Hussain SP, Trivers GE, Hofseth LJ, He P, Shaikh I, Mechanic LE et al. Nitric oxide, a mediator of inflammation, suppresses tumorigenesis. Cancer Res 2004; 64: 6849-6853.

18. Garcia-Navas R, Munder M, Mollinedo F. Depletion of L-arginine induces autophagy as a cytoprotective response to endoplasmic reticulum stress in human $T$ lymphocytes. Autophagy 2012; 8: 11.

19. Luiking YC, Ten Have GA, Wolfe RR, Deutz NE. Arginine de novo and nitric oxide production in disease states. Am J Physiol Endocrinol Metab 2012; 303: E1177-E1189.

20. Haines RJ, Pendleton LC, Eichler DC. Argininosuccinate synthase: at the center of arginine metabolism. Int J Biochem Mol Biol 2011; 2: 8-23.

21. Walters RG, Coin LJ, Ruokonen A, de Smith AJ, El-Sayed Moustafa JS, Jacquemont JS et al. Rare genomic structural variants in complex disease: lessons from the replication of associations with obesity. PLoS One 2013; 8: e58048.

22. Yang TS, Lu SN, Chao Y, Sheen IS, Lin CC, Wang TE et al. A randomised phase II study of pegylated arginine deiminase (ADI-PEG 20) in Asian advanced hepatocellular carcinoma patients. Br J Cancer 2010; 103: 954-960.

23. Nicholson LJ, Smith PR, Hiller L, Szlosarek PW, Kimberley C, Sehouli J et al. Epigenetic silencing of argininosuccinate synthetase confers resistance to platinum-induced cell death but collateral sensitivity to arginine auxotrophy in ovarian cancer. Int J Cancer 2009; 125: 1454-1463.

24. Szlosarek PW, Grimshaw MJ, Wilbanks GD, Hagemann T, Wilson JL, Burke F et al. Aberrant regulation of argininosuccinate synthetase by TNF-alpha in human epithelial ovarian cancer. Int J Cancer 2007; 121: 6-11.

25. Nagrath D, Soto-Gutierrez A. Reply to: 'Is the pathway of energy metabolism modified in advanced cirrhosis?'. J Hepatol 2014; S0168-8278: 00303-1.

26. Nishikawa T, Bellance N, Damm A, Bing H, Zhu Z, Handa K et al. A switch in the source of ATP production and a loss in capacity to perform glycolysis are hallmarks of hepatocyte failure in advance liver disease. J Hepatol 2014; 60: 1203-1211.

27. Glasauer A, Sena LA, Diebold LP, Mazar AP, Chandel NS. Targeting SOD1 reduces experimental non-small-cell lung cancer. J Clin Invest 2014; 124: 117-128.

28. Mullen AR, Wheaton WW, Jin ES, Chen PH, Sullivan LB, Cheng T et al. Reductive carboxylation supports growth in tumour cells with defective mitochondria. Nature 2012; 481: 385-388.

29. Metallo CM, Vander Heiden MG. Understanding metabolic regulation and its influence on cell physiology. Mol Cell 2013; 49: 388-398.

30. Metallo CM, Gameiro PA, Bell EL, Mattaini KR, Yang J, Hiller K et al. Reductive glutamine metabolism by IDH1 mediates lipogenesis under hypoxia. Nature 2012; 481: 380-384.

31. Le A, Rajeshkumar NV, Maitra A, Dang CV. Conceptual framework for cutting the pancreatic cancer fuel supply. Clin Cancer Res 2012; 18: 4285-4290.

32. Lu C, Thompson CB. Metabolic regulation of epigenetics. Cell Metab 2012; 16: 9-17.

33. Nagrath $D$, Caneba $C$, Karedath $T$, Bellance N. Metabolomics for mitochondrial and cancer studies. Biochim Biophys Acta 2011; 1807: 650-663.

34. Wang F, Zhang R, Xia T, Hsu E, Cai Y, Gu Z et al. Inhibitory effects of nitric oxide on invasion of human cancer cells. Cancer Lett 2007; 257: 274-282.

35. De Vitto H, Mendonca BS, Elseth KM, Vesper BJ, Portari EA, Gallo CV et al. Part II. Mitochondrial mutational status of high nitric oxide adapted cell line BT-20 (BT-20-HNO) as it relates to human primary breast tumors. Tumour Biol 2013; 34: 337-347.

36. De Vitto H, Mendonca BS, Elseth KM, Onul A, Xue J, Vesper BJ et al. Part III. Molecular changes induced by high nitric oxide adaptation in human breast cancer cell line BT-20 (BT-20-HNO): a switch from aerobic to anaerobic metabolism. Tumour Biol 2013; 34: 403-413.

37. Sen S, Kawahara B, Chaudhuri G. Mitochondrial-associated nitric oxide synthase activity inhibits cytochrome c oxidase: implications for breast cancer. Free Radic Biol Med 2013; 57: 210-220.

38. Cleeter MW, Cooper JM, Darley-Usmar VM, Moncada S, Schapira AH. Reversible inhibition of cytochrome $\mathrm{c}$ oxidase, the terminal enzyme of the mitochondrial respiratory chain, by nitric oxide. Implications for neurodegenerative diseases. FEBS Lett 1994; 345: 50-54.

39. Clementi E, Brown GC, Foxwell N, Moncada S. On the mechanism by which vascular endothelial cells regulate their oxygen consumption. Proc Natl Acad Sci USA 1999; 96 : 1559-1562.

40. Almeida A, Almeida J, Bolanos JP, Moncada S. Different responses of astrocytes and neurons to nitric oxide: the role of glycolytically generated ATP in astrocyte protection. Proc Natl Acad Sci USA 2001; 98: 15294-15299.
41. Maletic SD, Dragicevic LM, Zikic RV, Stajn AS, Kostic MM. Effects of nitric oxide donor, isosorbide dinitrate, on energy metabolism of rat reticulocytes. Physiol Res 1999; 48 417-427.

42. Li J, Hu X, Selvakumar P, Russell 3rd RR, Cushman SW, Holman GD et al. Role of the nitric oxide pathway in AMPK-mediated glucose uptake and GLUT4 translocation in heart muscle. Am J Physiol Endocrinol Metab 2004; 287: E834-E841.

43. Semenza GL. Expression of hypoxia-inducible factor 1: mechanisms and consequences. Biochem Pharmacol 2000; 59: 47-53.

44. Caneba CA, Bellance N, Yang L, Pabst L, Nagrath D. Pyruvate uptake is increased in highly invasive ovarian cancer cells under anoikis conditions for anaplerosis, mitochondrial function, and migration. Am J Physiol Endocrinol Metab 2012; 303: E1036-E1052.

45. Yang L, Moss T, Mangala LS, Marini J, Zhao H, Wahlig S et al. Metabolic shifts toward glutamine regulate tumor growth, invasion and bioenergetics in ovarian cancer. Mol Syst Biol 2014; 10: 728.

46. Chung JS, Park S, Park SH, Park ER, Cha PH, Kim BY et al. Overexpression of Romo1 promotes production of reactive oxygen species and invasiveness of hepatic tumor cells. Gastroenterology 2012; 143: 1084-1094 e1087.

47. Hung WY, Huang $\mathrm{KH}, \mathrm{Wu} \mathrm{CW}$, Chi CW, Kao $\mathrm{HL}$, Li AF et al. Mitochondrial dysfunction promotes cell migration via reactive oxygen species-enhanced beta5-integrin expression in human gastric cancer SC-M1 cells. Biochim Biophys Acta 2012; 1820: 1102-1110.

48. Goh J, Enns L, Fatemie S, Hopkins H, Morton J, Pettan-Brewer C et al. Mitochondrial targeted catalase suppresses invasive breast cancer in mice. BMC Cancer 2011; 11: 191.

49. Kumar B, Koul S, Khandrika L, Meacham RB, Koul HK. Oxidative stress is inherent in prostate cancer cells and is required for aggressive phenotype. Cancer Res 2008; 68: 1777-1785.

50. Du Q, Zhang X, Liu Q, Bartels CE, Geller DA. Nitric oxide production upregulates Wnt/betacatenin signaling by inhibiting Dickkopf-1. Cancer Res 2013; 73: 6526-6537.

51. Bellows CF, Jaffe BM. Glutamine is essential for nitric oxide synthesis by murine macrophages. J Surg Res 1999; 86: 213-219.

52. Ni Y, Schwaneberg U, Sun ZH. Arginine deiminase, a potential anti-tumor drug. Cancer Lett 2008; 261: 1-11.

53. Kelly MP, Jungbluth AA, Wu BW, Bomalaski J, Old LJ, Ritter G. Arginine deiminase PEG20 inhibits growth of small cell lung cancers lacking expression of argininosuccinate synthetase. Br J Cancer 2012; 106: 324-332.

54. Kim RH, Coates JM, Bowles TL, McNerney GP, Sutcliffe J, Jung JU et al. Arginine deiminase as a novel therapy for prostate cancer induces autophagy and caspase-independent apoptosis. Cancer Res 2009; 69: 700-708.

55. Feun LG, Marini A, Walker G, Elgart G, Moffat F, Rodgers SE et al. Negative argininosuccinate synthetase expression in melanoma tumours may predict clinical benefit from arginine-depleting therapy with pegylated arginine deiminase. Br J Cancer 2012; 106: 1481-1485.

56. Antunes $\mathrm{F}$, Boveris $\mathrm{A}$, Cadenas $\mathrm{E}$. On the mechanism and biology of cytochrome oxidase inhibition by nitric oxide. Proc Natl Acad Sci USA 2004; 101: 16774-16779.

57. Sen S, Kawahara B, Fry NL, Farias-Eisner R, Zhang D, Mascharak PK et al. A lightactivated NO donor attenuates anchorage independent growth of cancer cells: important role of a cross talk between NO and other reactive oxygen species. Arch Biochem Biophys 2013; 540: 33-40.

58. Maciag AE, Holland RJ, Robert Cheng YS, Rodriguez LG, Saavedra JE, Anderson LM et al. Nitric oxide-releasing prodrug triggers cancer cell death through deregulation of cellular redox balance. Redox Biol 2013; 1: 115-124.

59. Nakamura J, Asakura S, Hester SD, de Murcia G, Caldecott KW, Swenberg JA. Quantitation of intracellular NAD(P)H can monitor an imbalance of DNA single strand break repair in base excision repair deficient cells in real time. Nucleic Acids Res 2003; 31: e104.

60. Long AR, O'Brien CC, Malhotra K, Schwall CT, Albert AD, Watts A et al. A detergent-free strategy for the reconstitution of active enzyme complexes from native biological membranes into nanoscale discs. BMC Biotechnol 2013; 13: 41.

61. Bonome T, Levine DA, Shih J, Randonovich M, Pise-Masison CA, Bogomolniy F et al. A gene signature predicting for survival in suboptimally debulked patients with ovarian cancer. Cancer Res 2008; 68: 5478-5486.

(i) (\$) Cell Death and Disease is an open-access journal published by Nature Publishing Group. This work is licensed under a Creative Commons Attribution-NonCommercialNoDerivs 3.0 Unported License. The images or other third party material in this article are included in the article's Creative Commons license, unless indicated otherwise in the credit line; if the material is not included under the Creative Commons license, users will need to obtain permission from the license holder to reproduce the material. To view a copy of this license, visit http://creativecommons.org/ licenses/by-nc-nd/3.0/ 